\author{
Carolina Payares-Asprino ${ }^{1}$ \\ ${ }^{1}$ Mechanical Engineering Department Norwich University, Northfield, USA \\ mpayares@norwich.edu
}

\title{
PREDICTION OF MECHANICAL PROPERTIES AS A FUNCTION OF WELDING VARIABLES IN ROBOTIC GAS METAL ARC WELDING OF DUPLEX STAINLESS STEELS SAF 2205 WELDS THROUGH ARTIFICIAL NEURAL NETWORKS
}

\begin{abstract}
Dual-phase duplex stainless steel (DSS) has shown outstanding strength. Joining DSS alloy is challenging due to the formation of embrittling precipitates and metallurgical changes during the welding process. Generally, the quality of a weld joint is strongly influenced by the welding conditions. Mathematical models were developed to achieve high-quality welds and predict the ideal bead geometry to achieve optimal mechanical properties. Artificial neural networks are computational models used to address complex nonlinear relationships between input and output variables. It is one of the powerful modeling techniques, based on a statistical approach, presently practiced in engineering for complex relationships that are difficult to explain with physical models. For this study robotic GMAW welding process manufactured the duplex stainless steel welds at different welding conditions. Two tensile specimens were manufactured from each welded plate, resulting in 14 tensile specimens. This research focuses on predicting the yield strength, tensile stress, elongation, and fracture location of duplex stainless steel SAF 2205 welds using back-propagation neural networks. The predicted values of tensile strength were later on compared with experimental values obtained through the tensile test. The results indicate $<2 \%$ of error between observed and predicted values of mechanical properties when using the neural network model. In addition, it was observed that the tensile strength values of the welds were higher than the base metal and that this increased when increasing the arc current. The welds' yield strength and elongation values are lower than the base metal by $6 \%, \sim 9.75 \%$, respectively. The yield strength and elongation decrease might be due to microstructural changes when arc energy increases during the welding.
\end{abstract}

Keywords: Neural network; welding; mechanical properties

\section{INTRODUCTION}

Duplex stainless steels are alloys consisting of a two-phase microstructure with the balance between ferrite and austenite and combine high yield strength. Due to their excellent mechanical properties, duplex stainless steel is used in highly demanding applications such as petrochemical and offshore constructions [1]. Welding is one of the most critical and standard manufacturing processes used with these alloys. Duplex stainless steel presents good weldability, but care must be taken to ensure the continuity of the duplex microstructure of the weldment. 
During welding, the material is subjected to a very high heating and cooling rate. In many cases, this results in the ferritization of the fusion zone and the heat affected zone. The mechanical properties of the duplex stainless steel weld metal have a strong dependence on weld microstructure, which changes by the welding conditions. The depth of the penetration per single welding pass is the result of the proper welding condition to obtain not only a joint with high efficiency [2]. Robotic gas metal arc (GMA) welding is a manufacturing process used to produce high-quality joints and be utilized in automation systems to enhance productivity. Despite its widespread use in the various manufacturing industries, the mathematical models for the process parameters for given welding tasks need to be fully understood and quantified to achieve the complete automation of robotic GMA welding.

Palanivel et al. [3] employed response surface methodology (RSM) to develop the mathematical model for predicting the ultimate tensile strength, yield strength, and percentage of elongation of AA6351 aluminum alloy varying the process parameter in friction stir welding (FSW). These parameters were (FSW) such as rotational tool speed, welding speed, and axial force. They found an increase in the rotational tool speed, welding speed, and axial force leads to the increase in the ultimate tensile strength, and it reaches a maximum value and then decreases. Verna et al. investigated the influence of welding parameters of gas metal arc (GMA) welding on mechanical properties (tensile strength and hardness) of the joint of dissimilar aluminum alloys 6061-T6 and 5083-O. They found the mathematical model to predict tensile strength and weld hardness of the joint using Response surface methodology in GMA of dissimilar materials. Response surface methodology was found satisfactory $(<10 \%$ error) to optimize the process parameters of GMA welding of dissimilar AA6061-T6 and AA5083-O aluminum alloys [4].

Heidarzadeh et al. carried out the Prediction of the mechanical properties of friction stir welded pure copper joints using response surface methodology. The results showed that the developed models were reasonably accurate. The increase in welding parameters resulted in increasing the joints' tensile strength up to a maximum value. The elongation percent of the joints increased with increased rotational speed and axial force but decreased by increasing welding speed. In addition, the hardness of the joints decreased with the increase of rotational speed and axial force but increased by increasing welding speed. The joints welded at higher heat input conditions revealed more ductility fracture mode [5]. Luo et al. established the effects of welding process parameters and their interactions on quality indexes of spot welds of galvanized steel sheets using the non-linear multiple orthogonal regression assembling design [6].

ANOVA analysis predicted the ultimate tensile test, yield strength, and percentage of elongation of the A319 Aluminum joints [7]. Rao et al. [8] found the mathematical models using multiple regression methods can predict the depth of penetration and convexity index conventional P-GMAW of mild steel with reasonable accuracy. A mathematical model developed using second-order regression equations could be used satisfactorily to predict the tensile properties of AISI 1018 mild steel welds using the MIG welding process [9].The effect of different parameters on the welding condition and the burn-through risk for a T-shape steel joint during the in-service welding are analyzed using experimental tests and numerical analyses. The experimental data, together with a large set of results produced by the numerical simulation, are used to compose a user-friendly computer code based on the neural network algorithms to predict the temperature levels in the critical points for different welding conditions [10]. The welding strength of mild steel weld predicted by the developed ANN model was accurate from multiple regression analysis using a pulsed metal inert gas welding process [11]. Atharifa [12] introduced a method based on a genetically optimized neural network system (GONNS) to enhance the selection of the optimum parameters for the friction 
stir spot welding (FSSW) process in aluminum 6061. The procedure's efficiency in providing the maximum strength for the weld and the minimum plunging load was showed. Saoudi et al. developed an artificial neural network (ANN) model to predict tensile and impact properties of a submerged arc helical welded (SAHW) pipeline steel API X70 based upon its chemical composition. The results revealed that the developed model is very accurate and has a strong potential for capturing the interaction between the mechanical properties and chemical composition of welded high strength low alloy (HSLA) steels [13]. Sivagurumanikandan et al. studied the effect of the process parameters viz., welding speed, laser power, focal position, and pulse frequency on the weld strength of Nd: YAG pulsed laser-welded super duplex stainless steel (SDSS). They found that Neural network models predict the tensile strength more preciously than the regression model [14]. Other studies established that ANN would help determine the required value of welding process parameters to yield a specific welding strength and suitable for online process monitoring and control using $\mathrm{CO}_{2}$ laser-MIG hybrid welding process on AA8011 grade aluminum alloy [15].

Other neural network models predicted the optimization of the weld. Cortes et al. applied this model in the contribution of the various welding process parameters (pressure, current, and time) on weld quality characteristic of when joining advanced high-strength steels (AHSS) martensitic type with resistance spot welding (RSW) [16]. Thekkuden et al. investigated the prediction capability of the artificial neural network for weld quality assessment from the captured voltage signals in a gas metal arc welding process on SA 516 grade 70' s bead-on-plate and v-groove welds. The feed-forward back propagation neural network predicted the quality of test $\mathrm{v}$-groove welds accurately with a $90.9 \%$ prediction rate in their studies. The results proved that the developed method is promising for the immediate and early prediction of weld quality [17]. Kim et al. developed intelligent algorithms to understand relationships between process parameters and bead height of BAH32 steel using the GMA/ $\mathrm{CO}_{2}$ welding process [18]. Their results show that a neural network model could predict the bead height more accurately than the multiple regression method. Payares et al. applied the technique of Response Surface Methodology to develop a mathematical model which analyzed the various effect of GMAW parameter on the mechanical properties of Duplex Stainless Steels. They established that the arc current and arc energy are the parameters that had more impact on the DSS weld [19].

This paper presents the prediction of tensile strength, yield strength, elongation, and fracture under different welding parameters such as arc voltage, arc current, and welding speed through a neural network back-propagation method for the robotic welding process duplex SAF 2205 welds. The simulated data obtained from the neural network model developed was compared with the experimental values from the actual gas metal robotic welding specimen welds. The results show that the proposed model can predict the mechanical properties with reasonable accuracy.

\section{MATERIALS AND EXPERIMENTAL WORKS}

The material used for this research was a $6 \mathrm{~mm}$ thick plate of Duplex Stainless Steel SAF 2205. The chemical composition of the sample was obtained conducting a spectrographic chemical analysis SPECTROLAB 5L and following ASTM A1016 standards. Table 1 shows the chemical composition of SAF 2205 DSS and filler metal ER-2209 (electrode) of $1 \mathrm{~mm}$ diameter as recommended by ASTM A815and A789 procedures GMA welding process [20, 21]. 
Table 1. Chemical composition of the DSS SAF 2205 plate and ER 2209 filler metal, wt. \%

\begin{tabular}{cccccccccc}
\hline Material & $\mathrm{C}$ & $\mathrm{Si}$ & $\mathrm{Mn}$ & $\mathrm{P}$ & $\mathrm{S}$ & $\mathrm{Cr}$ & $\mathrm{Ni}$ & $\mathrm{Mo}$ & $\mathrm{N}$ \\
\hline SAF 2205 & 0.045 & 0.32 & 1.41 & 0.030 & 0.020 & 22.32 & 5.31 & 3.34 & 0.08 \\
ER 2209 & 0.015 & 0.54 & 1.87 & 0.023 & 0.006 & 23.31 & 9.81 & 3.77 & 0.14 \\
\hline
\end{tabular}

Robotic gas metal arc welding process (GMAW) FANUC 100iB® manufactured the single bead-on-plate welds on DSS under different welding conditions. Bead-on- plate welding was conducted in this research to avoid distortion, obtain suitable geometry, get rid of clamping, and eliminate the adjustments of gap and mismatch of welds. The recommended values for arc energy (AE) ranged between 0.5 and $2.5 \mathrm{~kJ} / \mathrm{mm}$ for stainless steel duplex SAF 2205 [22], and Equation 1 calculated the AE values. The bead-on-plate (BOP) welds were manufactured using the conditions shown in Table 2. Figure 1 shows a schematic drawing of $\mathrm{BOP}$ welds and dimensions of the plate.

Where:

$$
A E(\text { Arc Energy })=\frac{\text { Arc current } \times \text { Arc voltage } \times 60}{\text { Welding speed } \times 1000}
$$

AE (kJ/mm), Arc Voltage (V), Arc Current (A), Welding speed (mm/min).

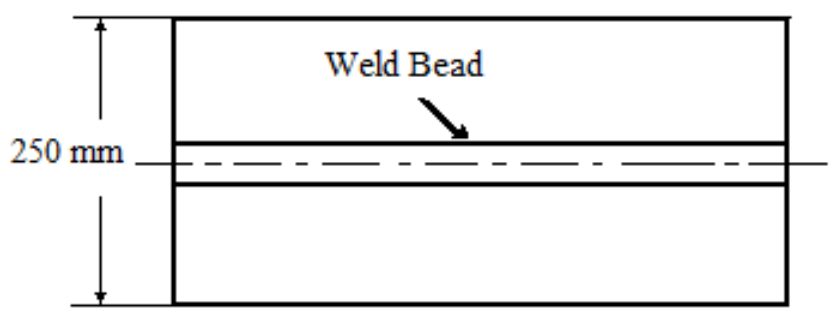

Fig. 1. Schematic drawing of the Bead on Plate (BOP) welds

Fanuc $100 i B \AA$ robotic welder only allows setting the arc voltage, the wire feed transfer (WFT), and the welding speed during the welding process. Figure 2 shows the correlation generated between the arc current and WFT.

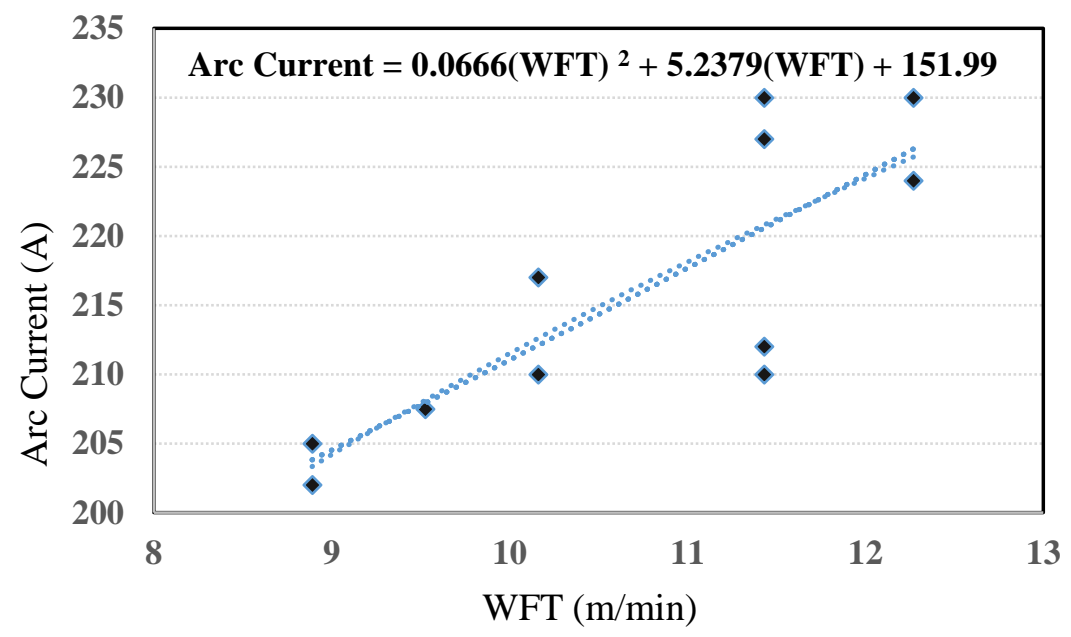

Fig. 2. Arc current vs WFT for FANUC 100iB [23] 
Table 2. Selected welding parameters

\begin{tabular}{cccccc}
\hline Sample & $\begin{array}{c}\text { Arc } \\
\text { Voltage } \\
(\mathrm{V})\end{array}$ & $\begin{array}{c}\text { WFT } \\
(\mathrm{m} / \mathrm{min})\end{array}$ & $\begin{array}{c}\text { Arc } \\
\text { Current } \\
(\mathrm{A})\end{array}$ & $\begin{array}{c}\text { Welding } \\
\text { speed } \\
(\mathrm{mm} / \mathrm{min})\end{array}$ & $\begin{array}{c}\text { Arc } \\
\text { Energy } \\
(\mathrm{kJ} / \mathrm{mm})\end{array}$ \\
\hline 1 & 28.00 & 11.43 & 212.00 & 480.00 & 0.740 \\
\hline 2 & 28.00 & 13.36 & 224.50 & 480.00 & 0.790 \\
\hline 3 & 30.00 & 11.43 & 230.13 & 480.00 & 0.860 \\
\hline 4 & 30.00 & 8.90 & 202.00 & 480.00 & 1.010 \\
\hline 5 & 30.00 & 8.90 & 205.00 & 480.00 & 1.230 \\
\hline 6 & 28.00 & 13.36 & 230.30 & 300.00 & 1.290 \\
\hline 7 & 30.00 & 11.43 & 226.25 & 300.00 & 1.360 \\
\hline
\end{tabular}

Figure 3 shows the tensile specimen mechanized after welding according to ASTM A370 code [24]. A mechanical testing machine brand MTS 810 model 976.04-14 with a $10 \mathrm{~mm} / \mathrm{min}$ test speed was used. Two tensile specimens from the base metal and two for each welding condition were prepared following ASTM E 8/E 8M-08 (Figure 3), resulting in 16 tensile samples tested [25].

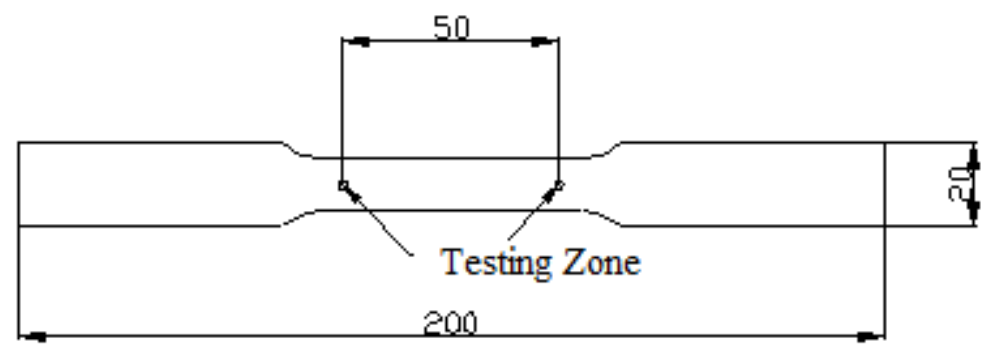

Fig. 3. Specification of Mechanized Tensile Test Specimen

\section{RESULTS}

Table 3 and Table 4 show the tensile properties of the DSS base metal and welds based on the process parameters, respectively. The results of the tensile tests of DSS welds, which comprise the yield strength $\left(\mathrm{S}_{0.2}\right)$, the tensile strength $\left(\mathrm{S}_{\mathrm{u}}\right)$, the elongation $(\varepsilon)$, and the fracture location. The uniaxial tensile test of the weldment for the welding condition of arc energy $0.74 \mathrm{~kJ} / \mathrm{mm}$ is plotted in Figure 4.

When analyzing the values in Table 3 and Table 4 , the tensile strength $\left(S_{u}\right)$ of the weld specimen is always higher than the strength of the base metal (BM) $\left(\mathrm{S}_{\mathrm{uBM}}\right)$. As observed in Table $4, \mathrm{~S}_{\mathrm{u}}$ increases by $\sim 3.5 \%$ when the arc current increases by $2 \%$, keeping the welding speed constant and increasing arc voltage by $\sim 7 \%$. This result agrees with previous research, were established that arc current has the most significant effect on tensile strength, and it increases with the increase of arc current [19].

This increase is probably related to a refinement of the ferrite-austenite phases. However, the yield strength values are lower by $6 \%$ than the base metal for lower values of arc energy $(\mathrm{AE}<1.09)$. As in previous research [26], the arc energy as a function of the welding process has a remarkable effect on the ferrite/austenite ratio. The lower arc energy (AE<1.09 kJ/mm) 
has resulted in a faster rapid cooling rate through the transformation temperature range, which influences the austenite content in this case by decreasing it [27]. Payares et al. also established that the arc energy has the strongest impact in the yield strength [19].

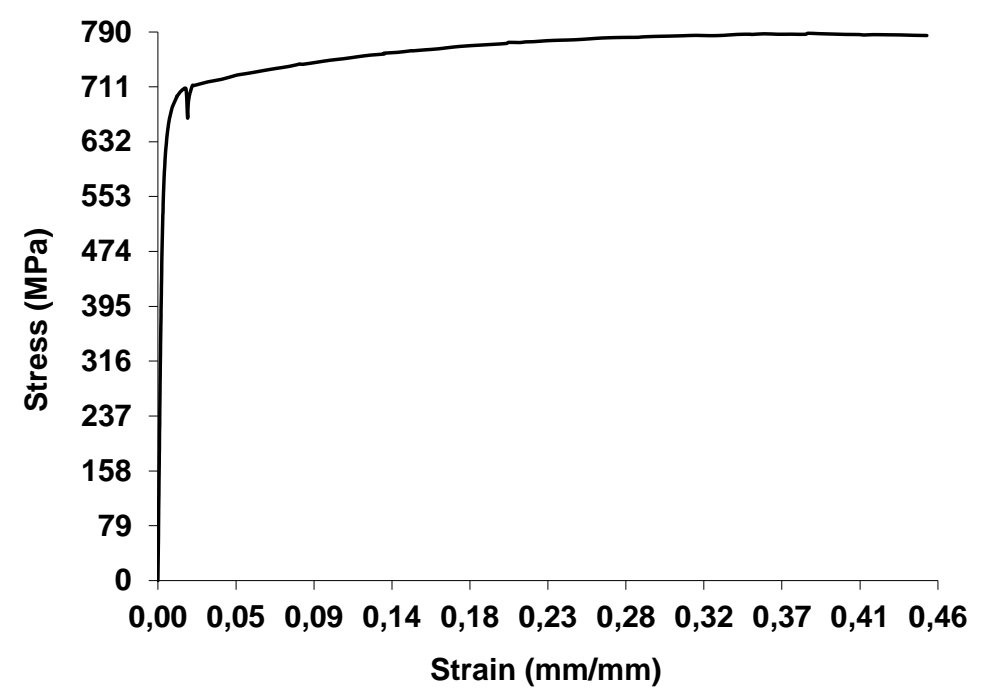

Fig. 4. Uniaxial tensile test of weldment sample along rolling direction for $\mathrm{HI}=0.74 \mathrm{~kJ} / \mathrm{mm}$ (sample 1B)

Table 3. Tensile testing results of DSS 2205 base metal

\begin{tabular}{cccc}
\hline Sample & $\begin{array}{c}\text { Yield strength } \\
\left(\mathrm{S}_{0.2}\right)(\mathrm{MPa})\end{array}$ & $\begin{array}{c}\text { Tensile strength } \\
\left(\mathrm{S}_{\mathrm{u}}\right)(\mathrm{MPa})\end{array}$ & $\begin{array}{c}\text { Elongation } \\
(\varepsilon)(\%)\end{array}$ \\
\hline Base Metal $_{\mathrm{avg}}$ & 627 & 789 & 38 \\
\hline
\end{tabular}

Table 4. Tensile testing results of DSS 2205 welds

\begin{tabular}{ccccc}
\hline Sample & $\begin{array}{c}\text { Yield strength }\left(\mathrm{S}_{0.2}\right) \\
{[\mathrm{MPa}]}\end{array}$ & $\begin{array}{c}\text { Tensile strength } \\
\left(\mathrm{S}_{\mathrm{u}}\right)[\mathrm{MPa}]\end{array}$ & $\begin{array}{c}\text { Elongation } \\
(\varepsilon)[\%]\end{array}$ & $\begin{array}{c}\text { Fracture Distance } \\
(\text { Xfr })[\mathrm{mm}]\end{array}$ \\
\hline 1A & 600 & 791 & 36 & 11 \\
1B & 600 & 792 & 34 & 13 \\
2A & 480 & 828 & 30 & 12 \\
2B & 651 & 834 & 33 & 12 \\
3A & 620 & 795 & 36 & 11 \\
3B & 620 & 795 & 36 & 10 \\
4A & 600 & 797 & 35 & 11 \\
4B & 573 & 814 & 38 & 12 \\
5A & 635 & 815 & 34 & 10 \\
5B & 650 & 808 & 35 & 12 \\
6A & 705 & 844 & 32 & 8 \\
6B & 620 & 832 & 34 & 9 \\
7A & 675 & 805 & 34 & 10 \\
7B & 655 & 803 & 33 & 11 \\
\hline
\end{tabular}

Figure 5 shows a visual relationship between the arc energy and the fracture location of the welded samples. All the fracture locations occurred in the Base Metal. 


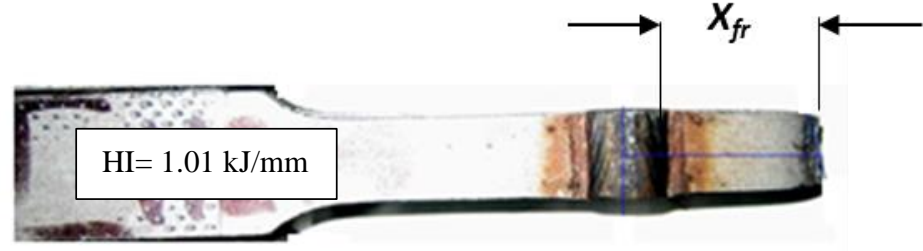

Fig 5. Photograph of fracture location distance (Xfr) of weld specimen (sample 4A)

The morphology for different welding conditions of DSS weld (Figure 6) shows that the weld pool is relatively deep at the center part and shallow near the border. This morphology was typical amongst most conditions. Weld bead is affected by the welding condition; when the arc energy increases $(>1.09 \mathrm{~kJ} / \mathrm{mm})$, both the width and height of the weld bead increases. The weld bead's enlargement might cause an increase in the $S_{0.2}$ by $\sim 10 \%$ for the $S_{0.2}$ for higher values of arc energy [28].

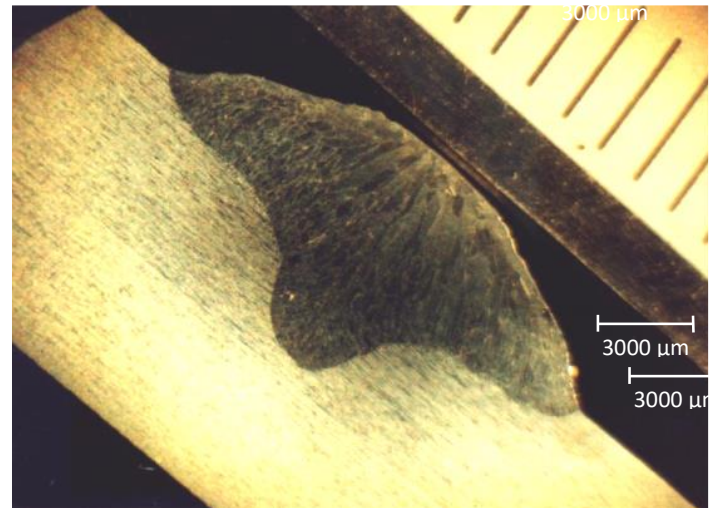

a) Sample $1 \mathrm{AE}=0.74 \mathrm{~kJ} / \mathrm{mm}(\mathrm{V}=28 \mathrm{~V}$; $\mathrm{I}=212 \mathrm{~A} ; \mathrm{WS}=480 \mathrm{~mm} / \mathrm{s}$ )

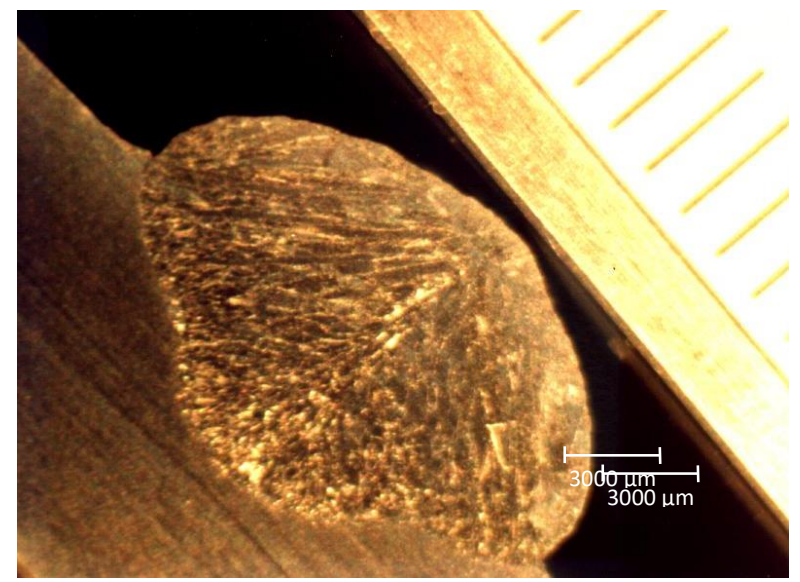

c) Sample 4 AE $=1.01 \mathrm{~kJ} / \mathrm{mm}(\mathrm{V}=28 \mathrm{~V}$; $\mathrm{I}=202 \mathrm{~A} ; \mathrm{WS}=480 \mathrm{~mm} / \mathrm{s}$ )

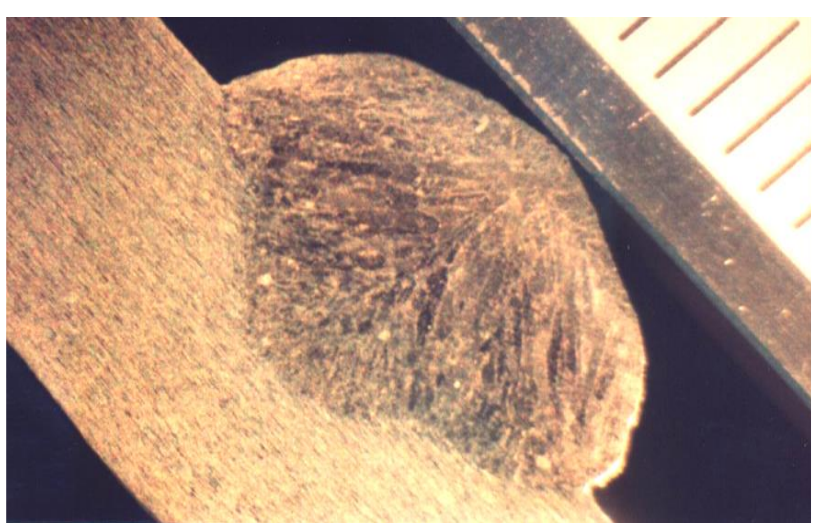

b) Sample $6 \mathrm{AE}=1.29(\mathrm{~V}=28 \mathrm{~V} ; \mathrm{I}=230 \mathrm{~A}$; $\mathrm{WS}=300 \mathrm{~mm} / \mathrm{min}$ )

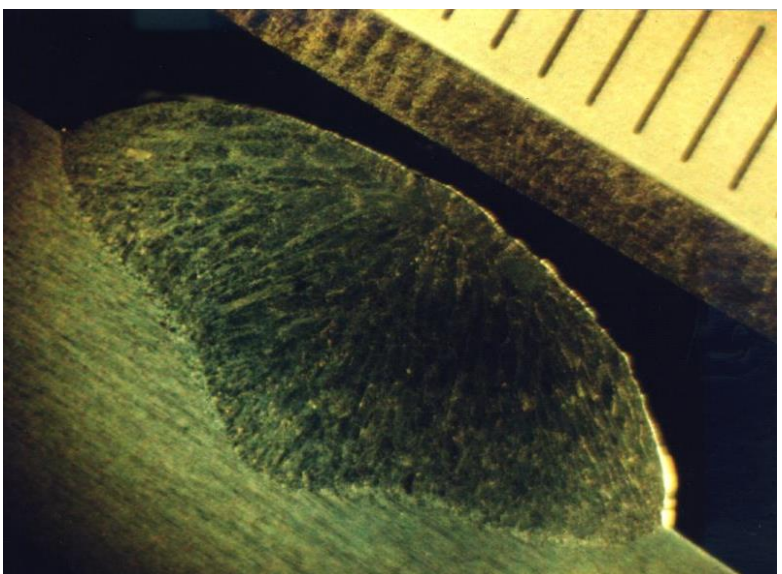

d) Sample $7 \mathrm{AE}=1.360 \mathrm{~kJ} / \mathrm{mm}(\mathrm{V}=30 \mathrm{~V}$; $\mathrm{I}=226 \mathrm{~A} ; \mathrm{WS}=300 \mathrm{~mm} / \mathrm{s}$ )

Fig 6. Photograph of DSS weld at different welding condition

Photomicrographs were taken using a LECO Olympus PMG3 field microscope, coupled to a PaxCAM camera. The Kalling \# 2 etchant $(5 \mathrm{~g} \mathrm{CuCl} 2,100 \mathrm{ml} \mathrm{H} 2 \mathrm{O}, 100 \mathrm{ml} \mathrm{HCl}$, and $100 \mathrm{ml}$ ethanol) was used to contrast the primary phases (ferrite and austenite). The optical 
microstructure of as-received 2205 DSS consists of elongated $\alpha$ and $\gamma$ grains, as shown in Figure 7, and the $\alpha / \gamma$ grain boundary appeared relatively flat and smooth. The measured volume fractions of $\alpha$ and $\gamma$ are about $51 \%$ and $49 \%$, respectively.

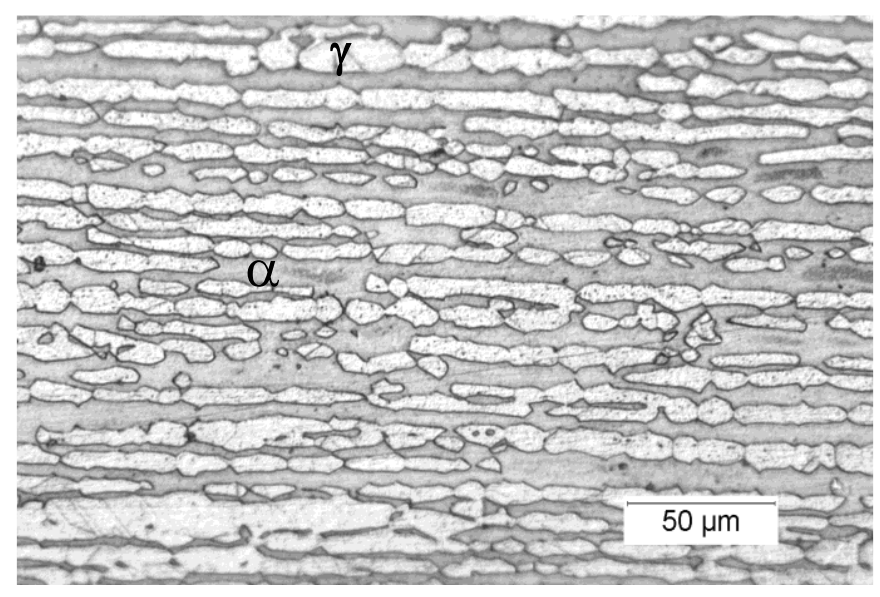

Fig. 7. Microstructure of DSS SAF 2205 base meatal that consist of ferrite $(\alpha)$ and austenite $(\gamma)$ grains

The ferrite content of DSS can considerably influence the yield strength and tensile ductility of the alloy [13]. It is further assumed that the arc energy manipulates these properties in a welded part and heat affected zone (HAZ) because the austenite to ferrite stability is related to the cooling rate. Payares et al. reported that the ferrite content in the fusion zone decreased with increasing arc energy for DSS robotic GMAW welds. Ferrite fraction in the weld metal varied from $56.2 \%(1.4 \mathrm{~kJ} / \mathrm{mm})$ to $63.2 \%(0.7 \mathrm{~kJ} / \mathrm{mm})$ [23]. The ferrite-austenite ratio depends on the arc energy during the welding process, as the latter controls the cooling rates and hence the extent of the diffusion-based ferrite-austenite transformation. Thus, nucleation of austenite is easier with a slow cooling rate (high arc energy and lower cooling rate). The increasing cooling time resulted in the appearance of intergranular austenite and Widmanstätten austenite (WA), which caused the higher measured austenite fraction [29]. Varbai et al. concluded that the most decisive factor in the austenite/ferrite ratio in the HAZ is the applied thermal cycle since there was no significant nitrogen loss. As the nitrogen diffusion governs the ferrite-to-austenite transformation in solid-state, the longer $\Delta \mathrm{t}_{12 / 8}$ cooling times will allow more time for diffusion. This mechanism causes a higher austenite content to develop in the HAZ, with no measurable nitrogen loss. The highest austenite content was 55\% in the HAZ. However, the nitrogen loss from the molten pool causes the austenite fraction in the weld metal (WM). The weld metal nitrogen content decreases as the arc energy increases. The BM's initial 56.6\% austenite fraction dropped down in the range of 31.8-14.3\% in the WM, increasing the arc Energy [30].

Baghdadchi et al. reported that changing the shielding gas from argon to nitrogen can increase the austenite content from 22 to $39 \%$ in the weld metal and $33 \%$ in the HAZ in laser welding duplex stainless steel [31].

Figure 8 shows the presence of the microstructures in different zones of the weld. Austenite is observed to form at the prior ferrite grain boundaries. Figures $8 \mathrm{a}$, and $8 \mathrm{~b}$, show that besides the ferrite, there are Widmanstätten Austenite (WA) plates into the grains of the weld metal and HAZ, respectively. WA is an over-heated structure generated using different thermal cycles, which deteriorates the mechanical properties of steels [32]. These microstructural changes in the weld metal and HAZ significantly affect the yield strength (at $\mathrm{AE}<1.1 \mathrm{~kJ} / \mathrm{mm}$ ), the strain at maximum load, and the fracture location. They tend to 
decrease when increasing the arc energy. Payares et al. also established that arc energy has the most substantial impact on the yield strength [19].

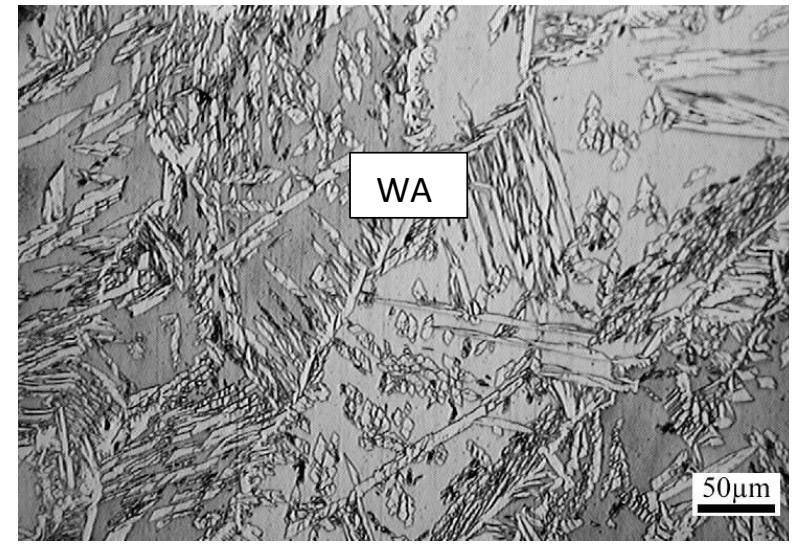

a)

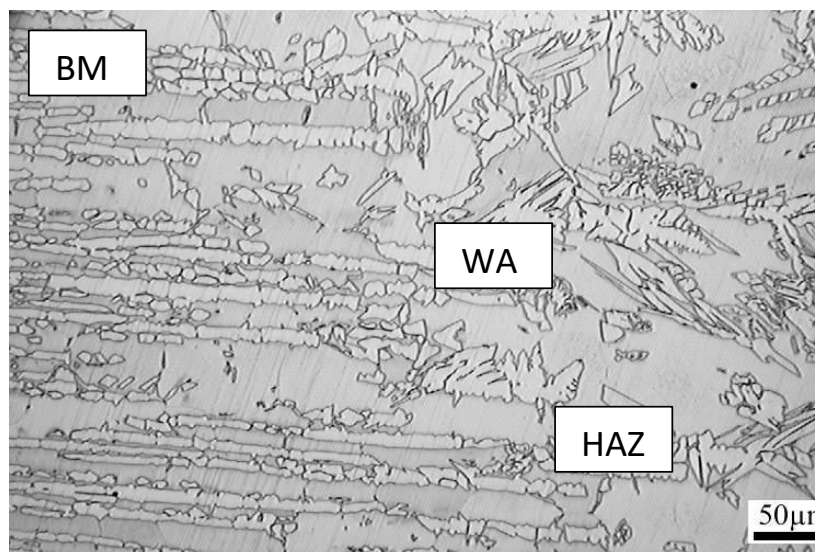

b)

Fig. 8. Microstructure of DSS SAF 2205 welds at $A E=1.26 \mathrm{~kJ} / \mathrm{mm}$ presents Widmanstätten austenite structure (WA) a) weld metal (WM) b) HAZ

\section{ARTIFICIAL NEURAL NETWORK FOR PREDICTING MECHANICAL PROPERTIES}

A neural network is composed of many nonlinear computational elements operating in parallel. Learning in a neural network means finding an appropriate set of connection strengths between the layer elements. Neural networks' design and training were carried out to predict the mechanical properties in specimens welded by GMAW robotic process. It used the artificial neural network of type backpropagation algorithm introduced by Haykin [33]. This method is widely applied in engineering studies due to its powerful ability in nonlinear interpolation. MatLab program ${ }^{\circledR}$ neural network toolbox adopted the "backpropagation" network [34,35]. Hidden and output layers utilized the Tangent Sigmoid and Pure-line Transfer Function. The input parameters for the neural network were arc voltage $(\mathrm{V})$, arc current $(\mathrm{A})$, welding speed $(\mathrm{mm} / \mathrm{sec})$, arc energy $(\mathrm{kJ} / \mathrm{min})$, and the wire feed transfer (WFT) (m/min). Table 2 shows the selected input parameters. Figure 9 illustrates the structure of the backpropagation neural network (BPNN) for this study. As Figure 9 shows, the arrays of this vector calculated the value of each neuron in the next layer (hidden layer). Tensile tests carried out for DSS welds provided the data to train the Artificial Neural Network (ANN) code. Table 4 listed the training sets. The outputs of ANN were: yield strength, tensile strength, elongation, and fracture location of the weld. 


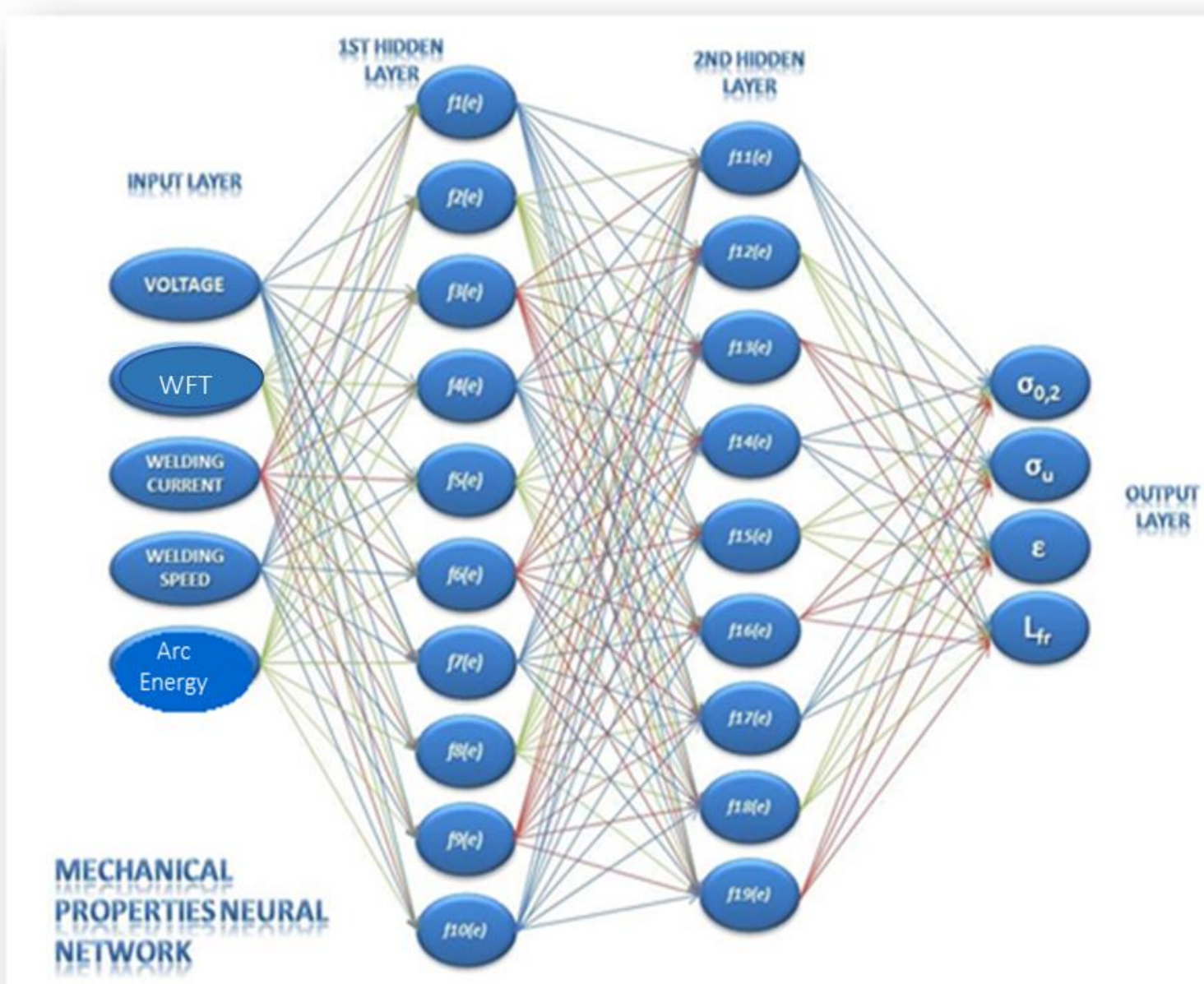

Fig. 9. Schematic Diagram of Back-propagation Neural Network for predicting Mechanical Properties of DSS welds

The holdout method, a reliable and straightforward approach, was employed to validate the developed ANN model [36]. One group of the input data was the training set used for computing the gradient and updating the network weight and biases. Another group chooses randomly from the input data was the validation data. The error value was calculated using the mean square error function (equation 1) and monitored during the training process [33].

$$
E(n)=\sum_{j} e_{j}^{2}(n)=1 / 2 \sum_{j}\left[d_{j}(n)-y_{i}(n)\right]^{2}
$$

Where $y_{i}(n)$ is the ouput neuron $\mathrm{j}$ and $d_{j}$ is the desired (target) response for that neuron.

The neural network behavior depends on the number of hidden layers and neurons present in them [37]. Therefore, to identify the most efficient combination of the neural network, numerous training modes based on the number of neurons, the number of hidden layers, and training repetitions have been made. The appropriate structure of the neural network to predict 
mechanical properties was chosen by trial and error. In this study, the design of the neural network was composed of six (6) neurons in the input layer, ten (10) neurons in the first occult layer, nine (9) neurons in the second hidden layer and four (4) neurons for the output layer.

As a result of the prediction of mechanical properties in DSS weldment using the robotic GMAW process, backpropagation-type neural network training was achieved, with less than $2 \%$ error in the prediction. The trained neural network predicted the tensile test results for the DSS bead on plate welds. The prediction of the mechanical properties reduces the uncertainty of the performance of the robotic welding process since it allows them to control their welding parameters and obtain expected behavior. Eighty-five percent of the input data were used for the training process, and fifteen percent were assigned to the validation.

The neural network training was through the values of the tensile test obtained from different welding parameters (Table 4). Figure 10 shows the validation values as yield strength $\left(\mathrm{S}_{0.2}\right)$, tensile strength $\left(\mathrm{S}_{\mathrm{u}}\right)$, elongation $(\boldsymbol{\varepsilon})$, and fracture location $\left(\mathrm{X}_{\mathrm{fr}}\right)$ as a function of arc energy. The error committed were in average for $\mathrm{S}_{0.2}(<2 \%)$, for $\mathrm{S}_{\mathrm{u}}(<2 \%)$, for $\varepsilon(<0.73 \%)$, and for $\mathrm{X}_{\mathrm{fr}}(<0.5 \%)$.

a)

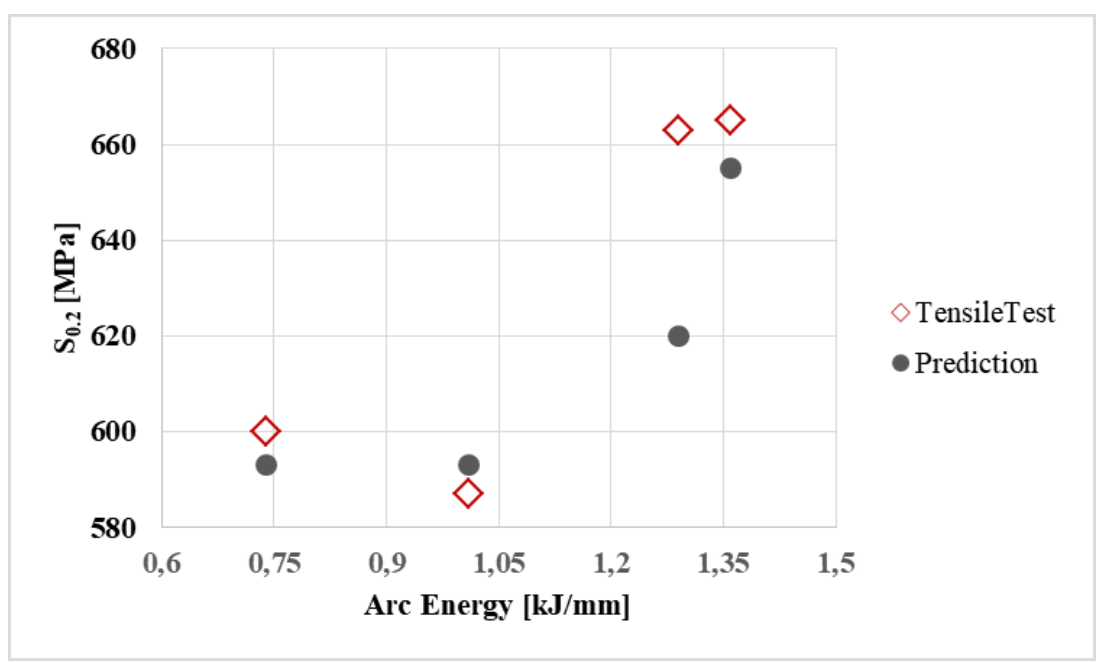

b)

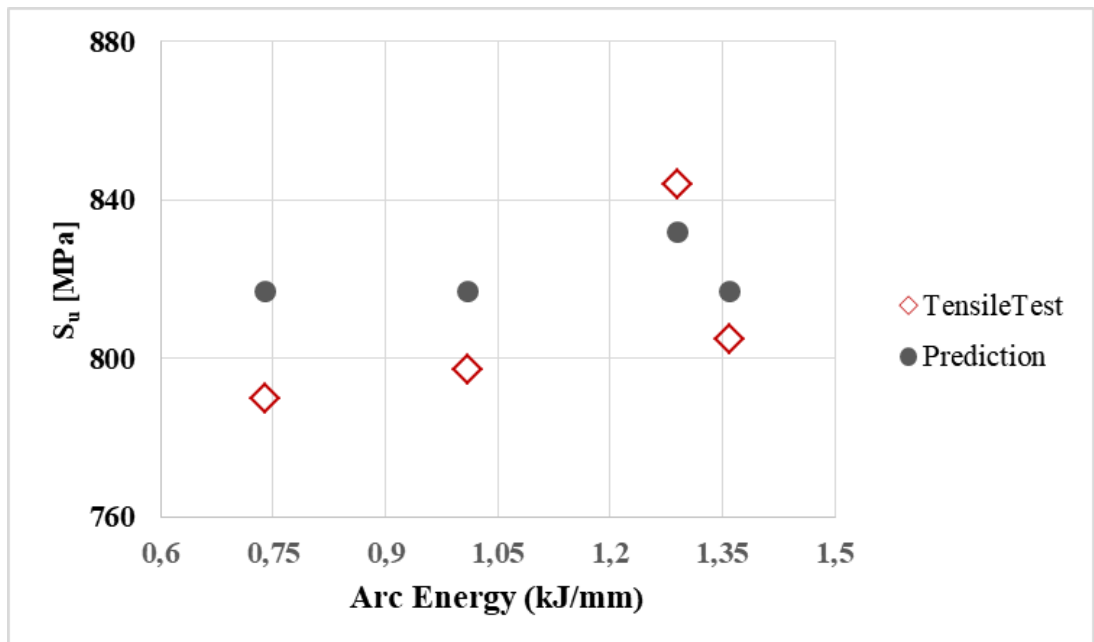


c)

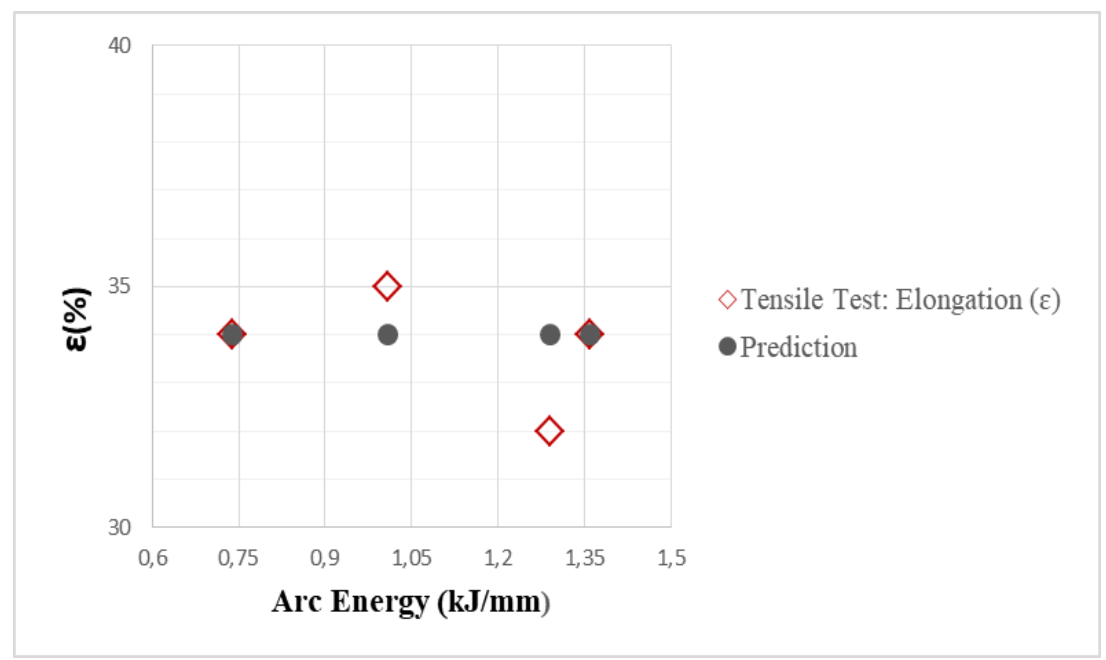

d)

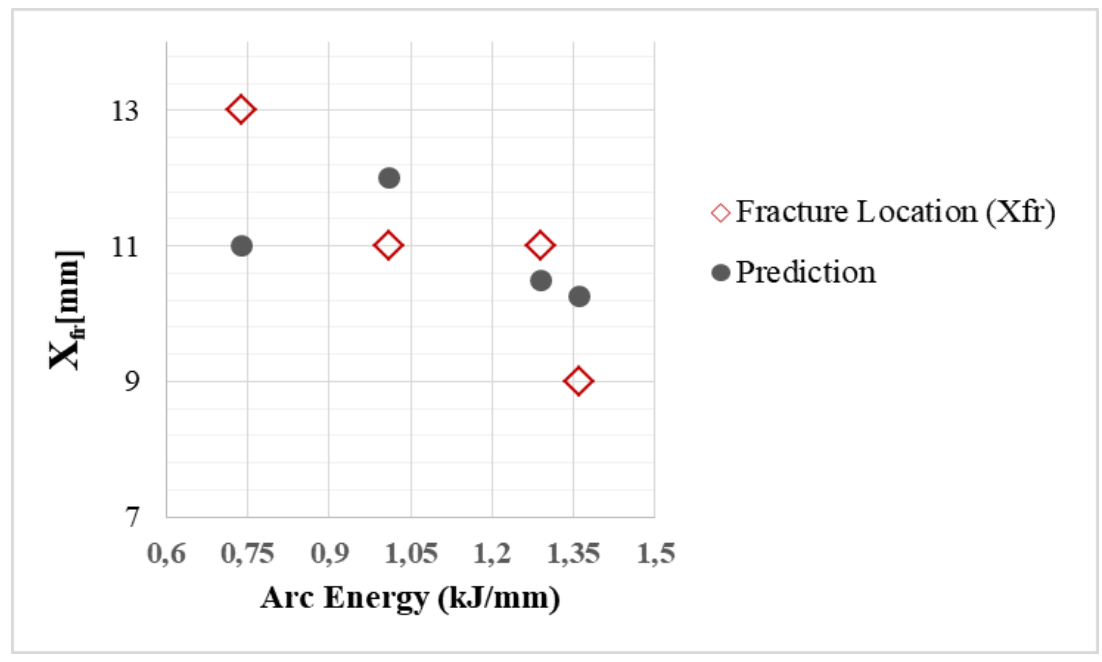

Fig. 10. Validation results of the network for the tensile test prediction of DSS mechanical properties at different Arc Energy (AE), a) Yield strength (S0.2) vs. AE, b) Tensile Strength (Su) vs.AE, c) Elongation ( $\varepsilon$ ) vs.AEl and

(d) Fracture location (Xfr) vs. AE

Figure 11 shows an example of the work of the MatLab ${ }^{\circledR}$ program during network training. It can say that the use of this "Toolbox" is a powerful tool in the design of neural networks for the optimization of tensile tests in robotic welding processes.

Best Validation Performance graph (Figure 12 a) shows the tendency of the network to yield convergent results and the decrease in the gradient of the error progressively (10.b). The progression of every training exercise showed a result where each line converged more accurately to the expected behaviour of the neural network. 


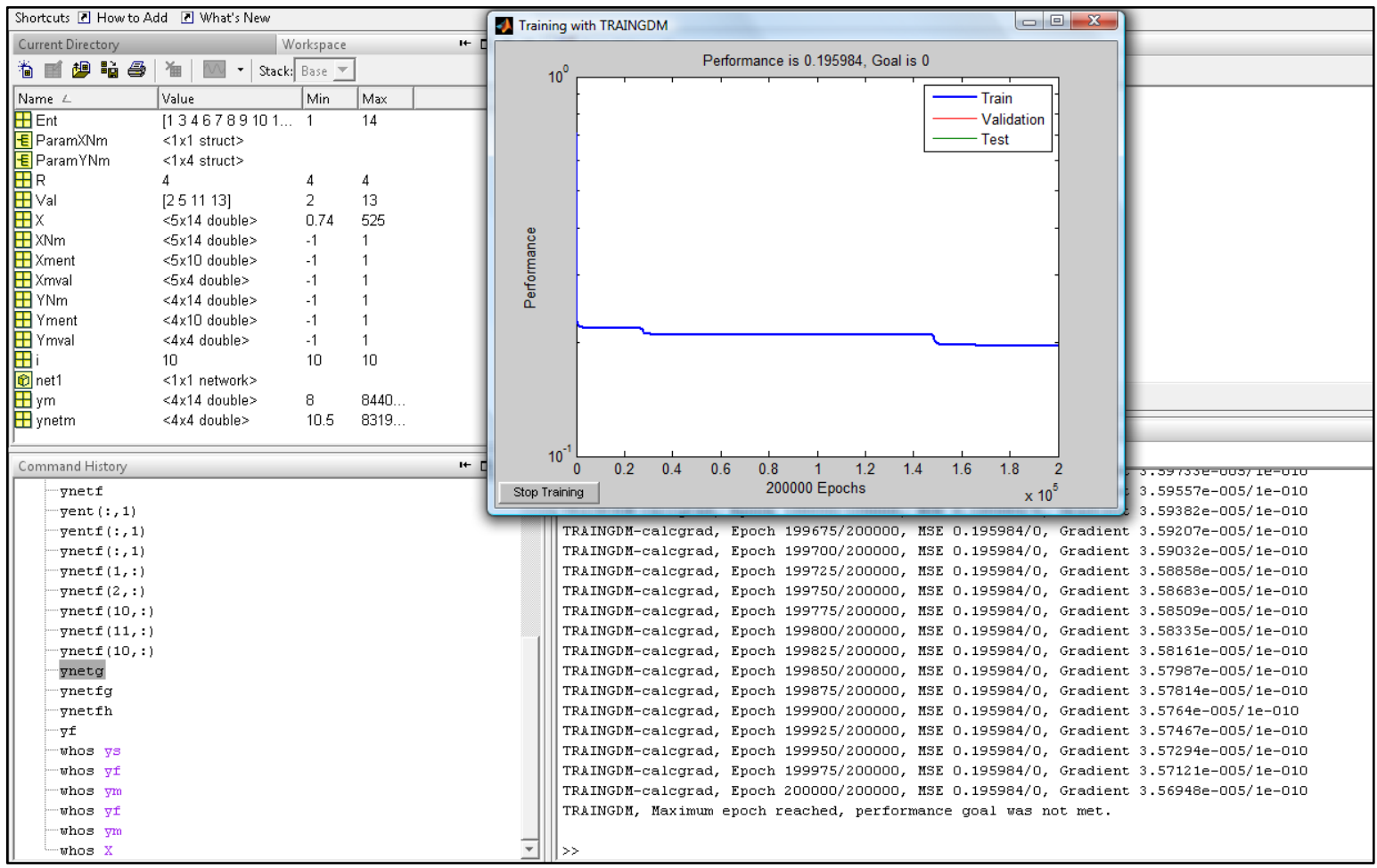

Fig. 11. View of the MatLab® program during Artificial Neural Network training. It shows the window of the data's convergence and the reported error

a)

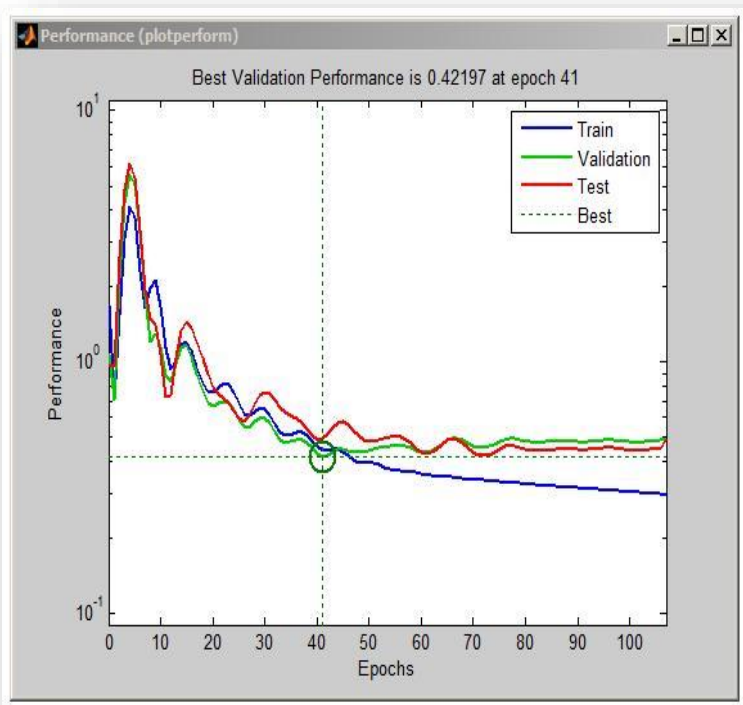

b)

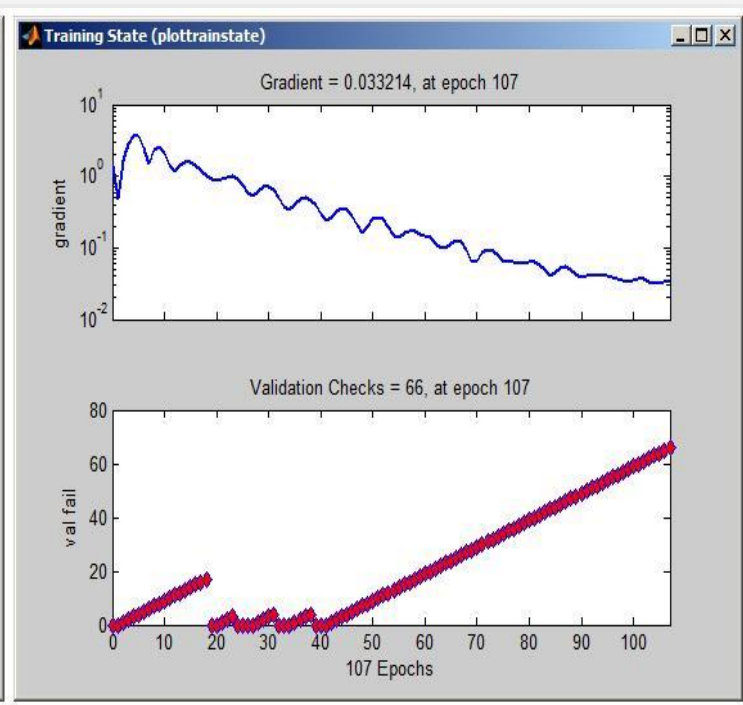

Fig. 12. View of the MatLab® program of the Convergent Behaviour of the Neural Network during validation 


\section{SUMMARY}

- Back-propagation neural network used for modeling mechanical properties showed reliable results when using it to predict mechanical properties for DSS robotic GMAW welds.

- Prediction of the mechanical properties of DSS welds compares well with the experimental data. The results indicate $<2 \%$ of error between observed and predicted values of tensile strength, yield strength, elongation, and location fracture when using the neural network model.

- It might increase the number of input data to decrease the error percentage and reach the ANN's accuracy.

- The tensile strength of the samples is higher than the base metal, and this increased when increasing the arc energy (AE). However, the yield strength values are lower by $6 \%$ than the base metal for lower values of arc energy $(\mathrm{HI}<1.09)$.

- Welding condition affects the weld bead of DSS; when the arc energy increases $(>1.09$ $\mathrm{kJ} / \mathrm{mm}$ ), both the width and height of the weld bead increases.

- The elongation $\left(\mathbf{e}_{\mathbf{u}}\right)$ tends to decrease when increasing the arc energy.

\section{ACKNOWLEDGMENTS}

The author would like to thank the Norwich University Faculty Development Funding for the Charles A. Dana Research Fellowship AY19-20 and the resourceful contribution of the Kreitzberg Library. The author is also grateful to the Colorado School of Mines for the support of this research, allowing use of the GMA welding FANUC 100iB® Robot.

\section{REFERENCES}

1. Ma M., Shrikrishna K.A., Sathiya P.: The impact of heat input on the strength, toughness, microhardness, microstructure and corrosion aspect of friction welded duplex stainless steel joints. Journal of Manufacturing Process 18 (2015) 92-106.

2. Zou Y., Ueji R., Fujii H.: Mechanical Properties of advanced active-TIG welded duplex stainless steel and ferrite steel. Materials Science and Engineering A 620 (2015) 140-148

3. Palanivel R., Mathews P.K., Murugan N.: Development of mathematical model to predict the mechanical properties of friction stir welded AA6351 aluminum alloy. Journal of Engineering Science and Technology Review 4 (1) (2011) 25-31.

4. Verma R. P., Pandey K.N.: Multi-response optimization of process parameters of GMA welding of dissimilar AA 6061-T6 and AA 5083-O aluminium alloy for optimal mechanical properties. Materials Today: Proceedings (2021) in Press.

5. Heidarzadeh A., Saeid T.: Prediction of mechanical properties in friction stir welds of pure copper. Materials and Design 52 (2013) 1077-1087. 
6. Luo Y., Liu J., Xu H., Xiong C., Liu L.: Regression modeling and process analysis of resistance spot welding on galvanized steel sheet. Materials and Design 30 (2009) 2547-2555.

7. Marichamy M., Babu S.: Experimental study and Taguchi optimization of process parameter on mechanical properties of A319 aluminum alloy using friction stir welding. Materials Today: Proceedings 39 (2021) 1527-1531

8. Rao S.P., Gupta O.P., Murty S.S.N., Rao A.K.: Effect of process parameters and mathematical model for the prediction of bead geometry in pulsed GMA welding. International Journal Advanced Manufacturing Technology 45 (2009) 45496 -505.

9. Kumar S., Singh, R.: Optimization of process parameters of Metal Inert Gas welding with preheating on AISI 1018 mild steel using grey based Taguchi method. Measurement 148 (2019) 106924.

10. Vakili-Tahami F., Majnoun P., Ziaei-Asl A.: Controlling the in-service welding parameters for Tshape steel pipes using neural network. International Journal of Pressure Vessels and Piping 175 (2019) 103937.

11. Pal S., Pal S.K, Samantaray A.K.: Artificial neural network modeling of weld joint strength prediction of a pulsed Metal Inert Gas welding process using arc signals. Journal of Materials Processing Technology 202 (2008) 464-474.

12. Atharifar H.: Optimum parameters design for friction stir spot welding using a genetically optimized neural network system. Proceedings of the Institution of Mechanical Engineer Part B: Journal of Engineering Manufacture 224 (2009) 403-418.

13. Saoudi A., Fellah M., Hezil N., Lerari D., Khamouli F., Atoui L., Bachari K., Morozova J., Obrosov A., Samad M.A.: Prediction of mechanical properties of welded steel X70 pipeline using neural network modelling. International Journal of Pressure Vessels and Piping 186 (2020) 104153.

14. Sivagurumanikandan N., Saravanan S., Kumar G.S., Raju S., Raghukandan K.: Prediction and optimization of process parameters to enhance the tensile strength of $\mathrm{Nd}$ : YAG laser welded super duplex stainless steel. Optik 157 (2018) 833-840.

15. Chaki S.: Neural networks based prediction modelling of hybrid laser beam welding process parameters with sensitivity analysis. SN Applied Sciences 1(10) (2019) 1-11.

16. Cortéz V.H.L, Valdés F.A.R, Treviño L.T.: Weldability of martensitic steel by resistance spot welding a neural network optimization in the automotive industry. Materials and Manufacturing Processes 24 (12) 1412-1417.

17. Thekkuden D.T., Mourad A-H.I.: Investigation of feed-forward back propagation ANN using voltage signals for the early prediction of the welding defect. SN Applied Sciences 1 (2019) 1615.

18. Kim I.S., Son J.S., Park C.E., Lee C.W., Yarlagadda K.D.V Prasad.: A study on prediction of bead height in robotic arc welding using neural network. Journal of Materials Processing Technology 130-131 (2002) 229-234.

19. Payares-Asprino C., Steele J.P.H.: Optimization of GMAW welding parameters in duplex stainless steel welds mechanical properties. Procedures of the ASME 2009 Pressure Vessels and Piping Division Conference; Prague, Czech Republic; PVP2009:77203.

20. ASTM A789/A789M-18 Standard Specification for Seamless and Welded Ferritic/Austenitic Stainless Steel Tubing for General Service; 2018.

21. ASTM A815/A815M-18 Standard Stainless Steel Specification for Wrought Ferritic, Ferritic/ Austenitic, and Martensitic Stainless Steel Piping Fittings; 2018.

22. AVESTA WELDING. How to Weld AVESTA SHEFFIELD. Sweden, Trade Literature, 2005. 
23. Payares-Asprino C, Patricia Muñoz-Escalona P.: Modeling to predict the percentage of ferrite as a function of heat input in Gas Metal Arc Welding of duplex stainless steel SAF2205 weldment. Proceedings of ESSC \& DUPLEX 2019 Conference 285-294.

24. ASTM A370.: Standard Test Methods and Definitions for Mechanical Testing of Steel Products, Edition 2019.

25. ASTM E8/E8M.: Standard Methods for Tension Testing of Metallic Materials, Edition 2018.

26. Muthupandi V., Srinivassa P.B., Asehadri S.K, Sundaresam S.: Effect of weld metal chemistry and heat input of the structure and properties of duplex stainless steel welds, Materials Science and Engineering A 358 (1-2) (2003) 9-16.

27. Vahman M., Shamanian M., Golozar M.A., Jalali A., Ahl Sarmadi M., Kangazian J.: The effect of welding heat input on the structure- property relationship of a new grade super duplex stainless steel. Steel Research International 91(1) (2020) 1900347.

28. Lee C-H., Chang K-Ho: Comparative study on girth weld-induced residual stresses between austenitic and duplex stainless steel pipe welds. Applied Thermal Engineering 63 (2014) 140-150.

29. Wu T., Wang J., Li H., Jiang Z., Liu C., Zhang H.: Reformation behavior of austenite in duplex stainless steel with rapid heat treatment. Steel Research International (90)2 (2018) 1800305.

30. Varbai B., Pickle T., Májlinger K.: Effect of heat input and role of nitrogen on the phase evolution of 2205 duplex stainless steel weldment. International Journal of Pressure Vessels and Piping 176 (2019) 103952.

31. Baghdadchi A., Hosseini A. V., Hurtig K., Karlsson L.: Promoting austenite formation in laser welding of duplex stainless steel-impact of shielding gas and laser reheation. Welding in the World 65 (2021) 499-511.

32. El-Batahgy A.M., Khourshid A.F., Sharef T.: Effect of laser beam welding parameters on microstructure and properties of duplex stainless steel. Material Science and Applications 2(10) (2011) 1443.

33. Haykin S.S.: Neural Networks: A Comprehensive Foundation, Macmillan College Publishing Company, New York, (1994) 138-229.

34. Beale M.H., Haga H.B., Demuth H.B.: Neural Network Toolbox ${ }^{\mathrm{TM}}$ user's guide. R22012a, the MathWorks, Inc., Apple Hill Drive Natick, 2012 MA 01760-2098.

35. Freeman J.A., Skapura D.M.: Algorithms, Applications, and Programming Techniques, AddisonWesley Publishing Company, USA, 1991.

36. Kanzow C., Yamashita N., Fukushima M.: Levenberg-Marquardt methods with strong local convergence properties for solving nonlinear equations with convex constraints. Journal of Computational Applied Mathematics 172 (2) (2004) 375-397.

37. Nagesh D.S., Datta G.L.: Prediction of weld bead geometry and penetration in shielded metal-arc welding using artificial neural networks. Journal of Materials Processing Technology 123 (2002) 303-312. 